\title{
Planning and Management of Construction Budgetary Costs
}

\author{
Helena Ellingerová \\ Slovak University of Technology in \\ Bratislava, Faculty of Civil Engineering \\ helena.ellingerova@stuba.sk
}

THE INTENTION OF EVERY INVESTOR IS TO OBTAIN CONSTRUCTION WORK IN THE MOST EFFECTIVE AND ECONOMIC MANNER. In other words the investor is trying to achieve the highest value for money for his capital investment. This goal can be achieved by systematic management of the investments throughout the planning process, design and construction phases of a project until the final account is paid and permission granted for use of the building. In order to achieve this, it is necessary to estimate the development cost during the planning and design phase and control or manage this cost throughout the project. The cost management process and the selection of a contractor are important factors for investor to achieve this goal.

\section{Keywords}

costs management, investment process, life cycle of a building, cost estimate, economic efficiency

\section{INTRODUCTION}

The investment process in constructing a new building or renovating an existing construction can progress in these following phases:

- development of the brief and assessment of the various solutions,

- study of performability of the conceptual option,

- detailed designing,

- selection of a contractor and agreement of the implicit works,

- project realization (construction process),

- handover of a building to the client and client's acceptance (Korytárová, 2011).

The person responsible for managing the project investment including the cost management is the project manager. One part of the investment process, cost management is not sufficiently managed in Slovakia. It would be convenient to apply methods of a project management to improve the quality of cost management.

The process of cost management runs throughout all the phases of the investment process and it is important that the construction project progresses with the same or lower construction cost than was estimated in tender phase. For that reason the project manager - quantity surveyor on behalf of investor should pay special attention to the cost planning of the construction to ensure it is detailed, sufficient, objective and complete. 


\section{Process of cost}

\section{management}

Cost management could be defined (include, consist of) as process of planning, interpretation, detailing, directing, agreement, cost control and evalu- ation of the construction during its preparation and constructing phases. This process is going on from throughout the building planning, projection and design, construction phases of a project until the final account is paid and permission for use of the building is granted.

The whole process of the cost management of a building is demonstrated in scheme 1.

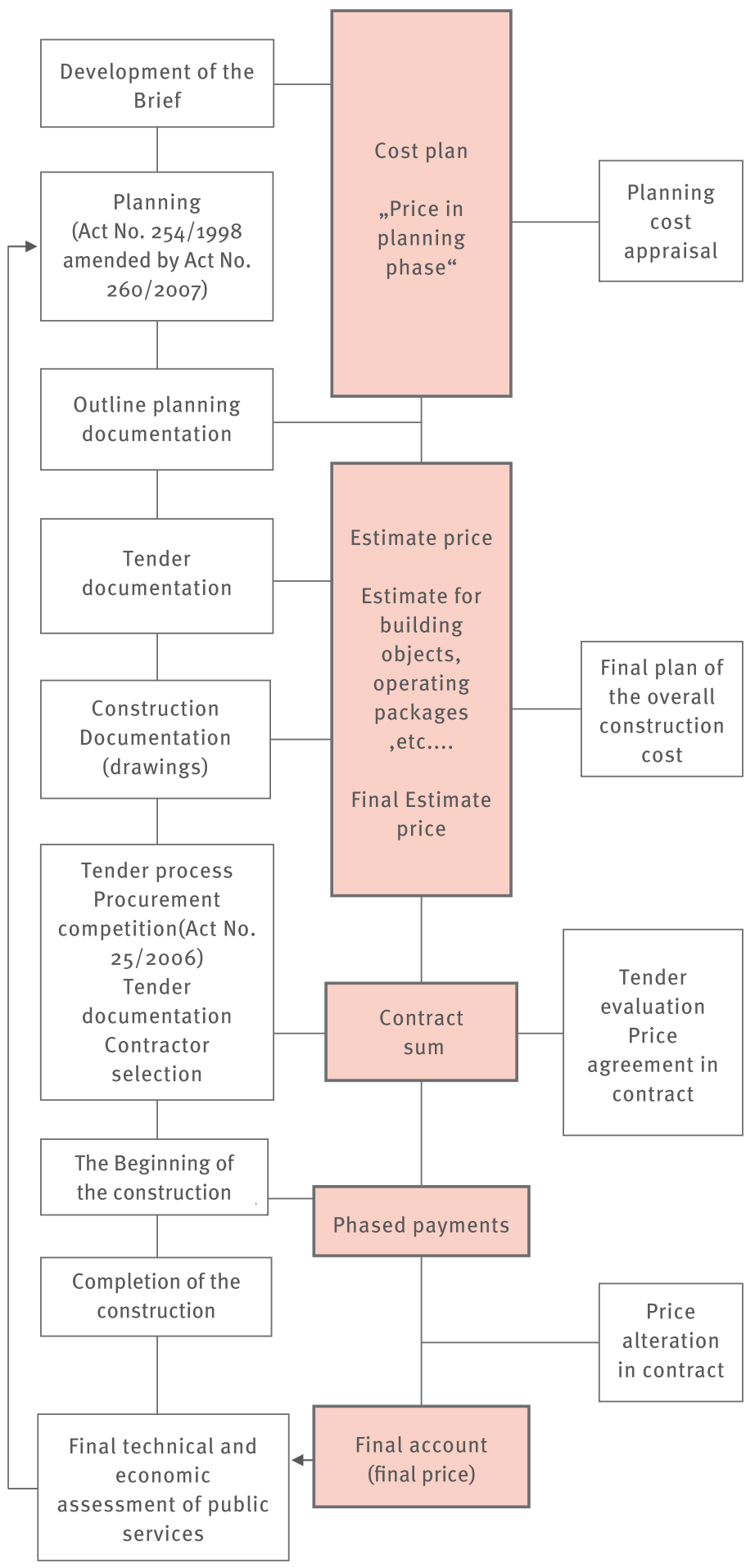


The main factors affecting the overall cost of a construction and the most important activities in cost management are:

\section{- Cost plan for planning which} presents price during the planning phase. The quantity surveyor uses this estimated cost to guarantee the financing of a construction.

- Cost estimation for building objects, operating packages and the final estimated price based on construction documentation (drawings, specifications and bill of quantities). In this phase tender documentation is completed for selecting the contractor and agreeing on the price of a construction.

- Thorough control of finished works and their cost for invoice purposes submitted by the contractor.

- Calculation of the final account, final technical and economical assessment of public services.

Since 1992 when the regulation No. 49/199 related to project preparation was annulled, the process of estimation and cost plan formation is not controlled by any other regulations neither by any consistent methodology. The process of cost management by investor or quantity surveyor is not ordered by any standards which means that investor decides how often and when the estimations and costs of a construction will be processed. The planning of an investment cost in the planning phase and final technical and economical assessment of public services are an exception as these are regulated by the law for public services.

The planning phase has to be developed by following regulations when the price for public services is higher than 1.327.756,75 €. This documentation also includes so called " price of public services" for planning.

The scheme of the cost management in the investment process is based on project planning being controlled/di- rected in such a way so the construction cost is not increased. The selection procedure of the contractor is regulated in order with current legislation for public procurement and this selection is realized by selected criteria.

Because the purpose of every investment project is to guarantee the economical efficiency it is necessary to research in the planning phase how will the construction concept and estimated cost affect future operating costs including costs for the maintenance and repairs of a building. For example the higher purchase cost for external cladding could reduce cost of the heating in the future. The same as using products or materials of better quality can reduce necessary repairs in the future etc (Szekeres, 2005).

The economical efficiency of a construction will be the higher the lower final cost paid during all the phases of a life cycle of a building will be paid.

It can be calculated by using the following formula:

$$
E_{1}=U_{1} / N_{1}=\max
$$

$E_{1}$ - economical efficiency of the investment

$U_{1}$ - achieved benefit

$N_{1}$ - the cost of an overall investment

Cost management of a building life cycle includes constant improvement of relationship between the value of $a$ building and its cost.

\section{Cost development during planning and realization}

The investor - quantity surveyor has the biggest influence on development of the cost of construction as in the phase of planning he determines the requirements of function, capacity, quality and final project terms and conditions. (Scheme No. 2). The purchase cost of a construction depends on these requirements. Every change of a type or quality of works and change of time scale causes the change of this cost. The requirements of quantity surveyor - investor are accomplished by architect's and engineer's appropriate suggestions in the project.

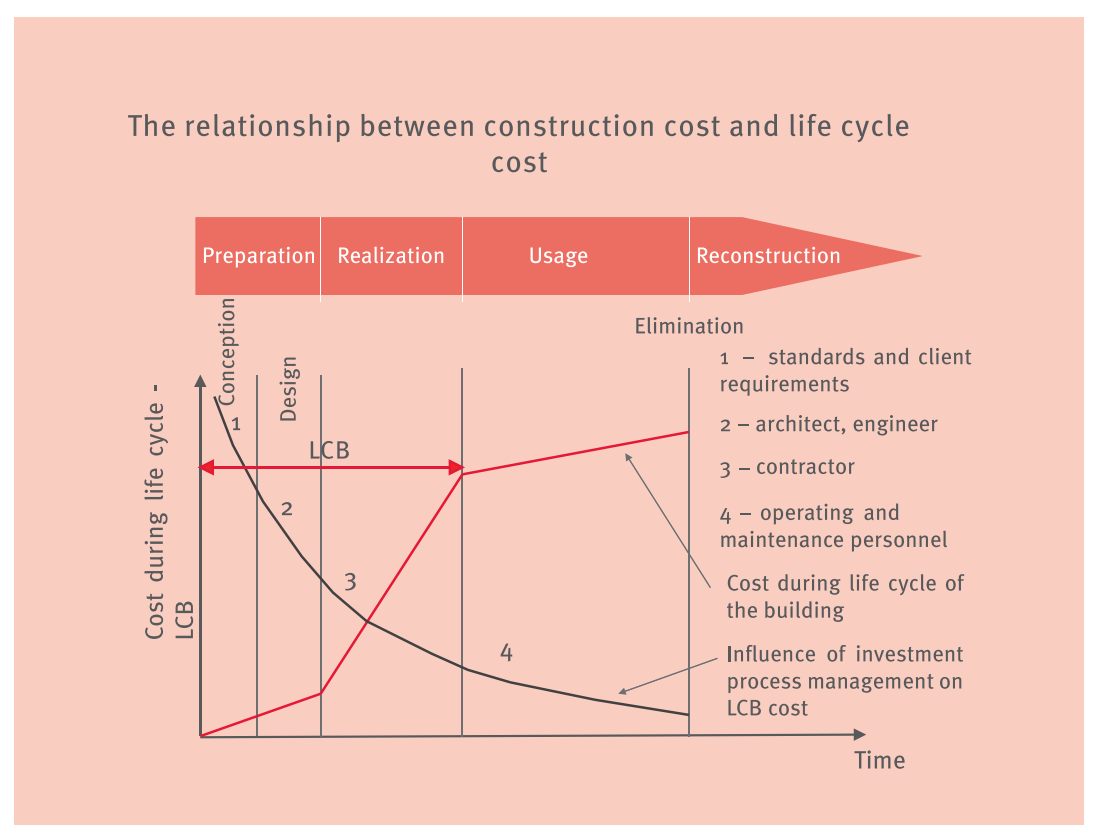

Scheme No.2: The final cost of a construction and life cycle of a building 
It is designers responsibility to follow Slovak technical standards during project preparation. Technical standards have direct impact on design solution as well as on construction cost. Technical standards are updated and adjusted to European standards. Construction cost cut-down can not be expected from this adjustment. The estimated cost can be affected during the design by creating several alternative projects and by selecting an effective solution including determination methods for cost analysis.

Organizations and authorities collaborating on project in terms of civil engineering law can also significantly influence building location and its content during the project generation. Individual group of investments consists of so called unavoidable investments. They form relatively big part in civil engineering. The client's competence is restricted in this case as the objections are being determinated by construction administration - board of works.

Architect - designer usually presents several options of a project to satisfy the requirements of client's brief and seeks approval from the investor to progress the project to the next stage. Every option has attached its own calculation of the overall construction cost. This calculation is the main criterion in the selection of the most convenient option.

\section{The structure/scheme of overall cost of the construction in the planning and realization process.}

Overall cost of the construction consists of payments for all the phases from planning to the beginning of usage of a building. It includes several different payments in connection with obtaining the whole range of services, operations, deliveries and works necessary for the whole realization process.
The calculation of the overall construction cost has been and still is used as a tool for financial planning for the construction procurement. According to the previous regulations for the project of the building, the construction costs were strictly provided at three times.

First it was estimation in the planning phase, second estimation was done with more accurate project - more accurate estimation. The third time there was "control formation of the cost" based on agreed "distribution costs". These costs were compounded in the same structure in all three cases and divided into $\mathrm{XI}$ chapters (following the regulation No. 43/1990 relating to the building project preparation). Construction costs are built up independently following the requirements of a contractor since 1992. Even though they can follow the original methodology.

The content and the structure of a construction cost by original methodology would be as follows:

I. The cost for project and investigation works (including authorized supervision, ground investigation, land survey, environmental research etc.). Price is based on the calculation of a cost and profit by $\%$ shared from estimated price of building objects or based on rates per hour.

II. The cost for the technology, facilities, fittings ant their installation (including their standard testing), are presenting the operating packages and after their installation they form the capital goods, costs for software facilities for computer aided system.

III. The cost for building objects (including their standard testing) and recultivation of landscape including planting of greenery, costs for elimination or removal of existing material possessions, costs for unavoidable investments including temporary objects and facilities.

IV. The cost for purchasing of capital goods which do not require the installation. They consist of costs for machin- ery, devices, equipment and inventory, which are presenting the basic assets and they are not part of operating packages of building objects.

V. The cost for works of art which is built in. They form the integral part of the architectural design of a construction. They are for example statues, wall paintings or painting works selected for this realization.

VI. The by-costs; if they are not included in any other parts. Its content is changing based on agreement between associates. It can change by objectification of the cost following real specific conditions of the actual realization. These could be costs for the transport away from the site, extremely difficult conditions for the transport, the area with difficult manufacturing conditions and particularly the cost for the site establishment.

When parties involved in this process negotiate about the way of counting in these costs the investor often requires the contractor to include this cost into the partial prices as a form of administrative expenses. However this causes less transparency of this cost.

VII. The cost for works provided by other than construction and installation companies; cost for obtaining patents and permissions - licence for future manufacture or services, costs for setting out works, surveying works, costs for landscaping works, for planting greens, building plantations, vineyards and hop-fields, costs for other works in connection with construction realization and costs which are not included elsewhere.

VIII. Unexpected costs; these are meant to be reserve of finances for covering increased costs in next phases of a design. This reserve is created by counting in \% part in costs in chapters II. and III. For example if there is higher unpredicted cost expected in renovation of a building $(20-30 \%)$ than in constructing a new building. For the new work it would be $10-20 \%$ of the costs in chapter II. and III. 
IX. The costs of other investments; these are used for purchasing of existing machinery and installations if they are not planned to be removed; tax payment for temporary or permanent usage of agricultural land for establishing the site etc.

$X$. The contribution money to other investors - clients; costs paid from investment resources, e.g. for project alternatives which were not used, or to build infrastructure by other investor and for purchasing basic facilities for liquidation including buying out properties from citizens.

\section{$X I$. The cost for engineering and com-} pletion works; these are costs in connection with construction preparation and insurance, indoor equipment with material possessions, costs for biological recultivation, tax payments for using public services and for environment protection, penalties and interest for mortgages etc.

This detailed classification can be used in creating costs for the construction even in the present and would help to avoid any failures. However not all the costs mentioned in chapters above are involved in every case.

For example in case of cost for the family house there are only costs for project, building objects, costs for the site establishment and possibly cost for purchasing the site apply. Processing of the cost of a construction starts in the planning phase and it begins with estimation of the cost plan for all the building objects and operating packages of a construction. The estimated cost for the structural and technical part of a construction presents basics for the cost estimation of a project and engineering works, costs for site establishment and other additional costs of unexpected works or eventually for others which are calculated by \% rate from relevant basis. In the final estimated construction price which is issued with the project documentation, the construction cost is based on the cost of items of the building objects and operating packages. The other items of the construction cost are calculated more accurately within the estimation of a cost plan.

This above mentioned structure of the cost of a construction can be used in accordance with the Act No. 254/1998 of the law digest as amended by the Act No. 260/2007 of the law digest related to public services which came into operation on 1st of August 2007. As mentioned later the construction cost is formed into eight sections in accordance with this Act. The planned public services are organised in time scale in accordance with the Act related to public services. Their financing is provided by capability of a state budget and by approved limit for each single year of the realization.

The public service is in this Act explained as activity for preparation and realization of a construction which is financed partially or fully by public finances.

Public finances are finances of a state budget, state funds, and state property funds of Slovak Republic, of loans guaranteed by state which are used for preparation, realization and assessment of public works including modernization of technical facilities.

The extent of the documentation for planning is developed in accordance with the regulation No. $83 / 2008$ of the law digest. The cost or price of public services in planning phase is part of an economic report where costs are divided as follows:

a/ public services planning - preparation,

b/ structural part (building objects including technical facilities),

c/ technical part (operating packages, machinery and devices, equipment and inventory),

d/ site establishment,

e/ assumed unavoidable investments, f/ purchasing of site applies, tax pay- ments for buying out the land, patents, licences etc., $\mathrm{g} /$ the reserve set in extent $8-12 \%$, $\mathrm{h} /$ other not mentioned investments.

The following data are applicable to determine estimated costs:

a/ comparable options obtained from statistic data,

b/ specific cost investment,

c/ international comparisons,

d/ type documents (records),

e/ comparable projects,

$\mathrm{f} /$ research projects,

$\mathrm{g} /$ repeated projects.

After finalization of public services its client's responsibility to provide final technical and economical evaluation of public works. This evaluation is completed by review of actual cost in prescribed structure in compliance with specifications presented in appendix of the regulation No. 83/2008 of law digest. The data summary of completed public works as well as about the other constructions is very important in formation of the database of the current price and technical and economical index. These are essential in preparation of new projects.

\section{Conclusions}

The cost of construction can be determined with various accuracy. It depends on standard and level of the processing project. This can be done by brief estimation, by the cost plan estimation or by the final price estimation. In case when only rough volumetric and technical data about overall construction are known the cost of construction is briefly estimated. This happens in the initial stage of a project. In this stage the investor forms the concept of purpose and size of a construction. The object structure is often not finalized yet hence it is not possible to use available cost factors of construction objects. The cost estimation is mostly created by comparison with cost of existing buildings. Whenever the capacity of 
an object is known the cost factors can be used per item, for example cost per one bed in hospital, cost per one parking space or cost per seat in cinema etc. If the financial resource is limited the investor can set the maximum limit of finances which will determine different steps taken in project so the final overall cost would not get over this limit.

The cost plan estimation is a preliminary price calculation. It can refer to the whole construction or only its part. The calculation of the final price estimate is an overview of the costs calculated in cost plan estimation of an individual building objects, operating packages and another costs related to the procurement of construction. The cost plan estimation is usually made as a part of the planning documentation or as a part of the outline planning documentation. The outline planning documentation contains relevant information about material and technical part of building objects and operating packages but it is not detailed enough for the final price estimation.

The cost plan estimation for one building object presents very simple and quick calculation to get an informative price per building object. It is worked out by using the cost factors. These factors are created from data about existing building objects and they present the price (basic cost) re-counted to one unit of measure of a building object. Certain amount of information about the building object is needed for its classifying into the range of existing objects - classification and for calculation of its extent in appropriate units of measure. After that, the cost factor can be determined for an informative price estimation.

The final price estimation for the job presents price calculation. The result of this price calculation is estimate price for construction works.

The final price estimation is made for the overall construction. It is designer's responsibility to provide this estimation as a part of the project documen- tation. The purpose of this so called check estimation is to provide relevant information about assumed price for construction works regarding to the project.

On the other side the contractor who was selected by investor or the contractor who won the competition work out and provide the contract sum.

The difference between the check estimation and contract sum or the difference in contract sums provided by different contractors is caused by the difference in input data for the calculation. It is caused by applying the principle of free price formation. This principle allows to create competition on the construction works market.

To make up contract sum it is essential to have detailed documentation which includes construction drawings. To save the cost for the construction drawings, tender documentation - drawings is often being used in phase of the realization. For that reason it would be sufficient to modify the methodology of preparing the project documentation.

Difficulties in cost management of constructions are on the quantity surveyor side in public procurement of construction works. It is mainly insufficient activity of the project manager in cost control, low specialized skills of workers and lack of interest on economical results of a project. This occurs mainly in preparation of documents for selection of contractor as well as in next phases of the selection procedure. In terms of the construction cost management it is important to determine contract conditions of price agreement, possibilities of price changes, price for additional works (works not included in quotation) and form of invoice issuing and payments for completed works.

It is important to improve quality of works of construction supervisor and pay more attention to listing and agreeing on the amount of finalized works in construction phase.

\section{References}

Ellingerová, H., Kalinová, G. (2010). The Economy of Construction. Textbook.

Bratislava: Building faculty STU, (p.67125).

Korytárová, J. and team. (2011). Management of Risks Relating to the Supply of Construction Work. Institute of Civil Economy and Management. Brno: Faculty of Civil Engineering.

Pilcher, R. (1992). Principles of Construction Management. London: McGraw-Hill Book Company.

Szekeres, K. (2005). Town as a participant of development process. In: Management of hazard in development process. Almanac from scientific course. Bratislava: Institute of management STU, (p. 113-118).

Law No. 254/1998 public works in response to the law 260/2007. Web site: Ministry of Justice, available at: http://jaspi.justice.gov.sk (accessed 19. April 2011).

Regulation of the Department for construction and regional development No. 83/2008. Web site: Ministry of construction and regional development, available at: www.build.gov.sk (accessed 19. April 2011). 